\title{
Welcome from the Conference Chairs
}

It was our pleasure to welcome you to the $22^{\text {nd }}$ International Conference on Conceptual Structures, which was held at the University of Savoie in Annecy, France. The conference location offered ample opportunities for sightseeing and outdoor activities with the Mont-Blanc summit nearby.

The idea of a colocation of ICCS and the International Conference on Formal Ontology in Information Systems (FOIS) in the French Alps germinated in a few brains in Mumbai in January 2013, during ICCS 2013 whose audience was quite small. We wanted to revitalize ICCS by renewing the program committee around a preserved historic core, in order to build relationships with new communities. ICCS 2014 in Iasi in Romania was an important first step in that direction. For ICCS 2016 we have assembled an excellent technical program, and the colocation with the $9^{\text {th }}$ International Conference on Formal Ontology in Information Systems offers even more opportunities to attend high-quality research presentations and additional workshops. That co-location which took place in Annecy, was unanimously supported by the ICCS Steering Committee, is a beautiful concretization of our will.

Two highlights of this year's program were the keynote addresses delivered by two renowned researchers. Dr Mateja Jamnik, from the Cambridge University Computer Laboratory, has made significant research contributions to the Diagrams and Automated Reasoning communities. Her research aims to investigate and mechanise human mathematical reasoning, such as the use of diagrams in proofs. Dr Jamnik delivered a keynote talk entitled Automating human-like reasoning with diagrams on machines. The topic of her talk reflected our drive to broaden the community from which ICCS aims to attract both paper submissions and delegates attending the conference. Dr Fabien Gandon is research Director in Informatics and Computer Science at Inria Sophia Antipolis méditerranée and the Inria representative at the World-Wide Web Consortium (W3C). His professional interests include: Web, Semantic Web, Social Web, Ontologies, Knowledge Engineering and Modelling, Mobility, Privacy, Context-Awareness, Semantic Social Network / Semantic Analysis of Social Network, Intraweb, Distributed Artificial Intelligence. Dr Gandon delivered a keynote entitled On the many graphs of the Web and the interest of adding their missing links.

ICCS 2016 received 40 full paper submissions from authors spanning 23 countries. These papers were independently and anonymously reviewed, typically by four members of the Program Committee. After the reviews and an initial round of discussions amongst the reviewers and Program Chairs, the authors were invited to submit rebuttals. To ensure a high quality program, the rebuttals were discussed and final versions of the reviews were produced. At the end of this process, the Program Chairs selected 14 full papers, giving a competitive acceptance rate of $35 \%$. A further five short papers were accepted for presentation and publication alongside six posters.

As with any organizational task of this scale, very many people have contributed to the success of ICCS 2016. We would especially like to thank the members of the Program Committee for their expert reviews and for their excel- 
lent engagement with the two discussion phases. The Program Committee also invited other experts to provide reviews for some papers, and we are grateful for their important contributions. We would also like to thank the following individuals: Richard Dapoigny and Patrick Barlatier who made all of the local arrangements; Juliette Dibie, Liliana Ibanescu, Stéphane Dervaux for liaising with Springer and compiling the proceedings; Cassia Trojahn dos Santos for taking care of the conference finances and sponsorship; Sven Linker for publicizing the conference; Nicolas Seydoux and Rémi Cavallo for being the web master and web site designer respectively. We are also grateful to the Steering Committee for their support and for entrusting us to organize ICCS 2016: Madalina Croitoru, Frithjof Dau, Ollivier Haemmerlé, Uta Priss, and Sebastian Rudolph. Finally, we thank our sponsors: Université Savoie Mont Blanc and Inria for financially supporting the conference organisation, and AFIA, the French Society on AI, for sponsoring the Best Paper Award.

We hope that you found the conference and its co-located events exciting and stimulating.

\section{Ollivier Haemmerlé \\ General Chair}

Catherine Faron Zucker and Gem Stapleton

Program Co-Chairs 